\title{
Evaluation of lipoic acid topical application on rats skin wound healing ${ }^{1}$
}

\author{
Irene Clemes Külkamp-GuerreiroI, Marielly Nunes Souza ${ }^{I I}$, Mariana Domingues Bianchin"I, Mateus Isoppo" ${ }^{\text {II }}$ Joana Sachetti

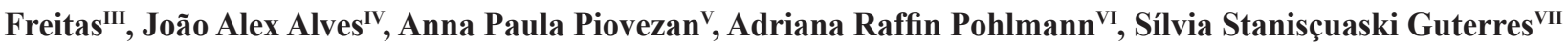 \\ ${ }^{\mathrm{I}} \mathrm{PhD}$, Associate Professor, Graduate Studies Program in Pharmaceutical Sciences, Faculty of Pharmacy, Federal University of Rio Grande do Sul \\ (UFRGS), Porto Alegre-RS, Brazil. Conception and design of the study, acquisition and interpretation of data, statistical analysis, English language, \\ manuscript writing, final approval of the version to be published. \\ IIGraduate student of Pharmacy, University of South Santa Catarina, Tubarao-SC, Brazil. Acquisition and interpretation of data.

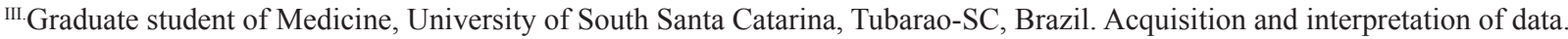 \\ ${ }^{\text {IV }}$ Master, Full Professor, Department of Pathology, Medical School, University of South Santa Catarina, Tubarao-SC, Brazil. Acquisition and \\ interpretation of data. \\ vPhD, Full Professor, Master Program in Health Sciences, University of South Santa Catarina, Tubarao-SC, Brazil. Conception and design of the study, \\ acquisition and interpretation of data, manuscript writing, final approval of the version to be published. \\ ${ }^{\mathrm{VI}} \mathrm{PhD}$, Associate Professor, Organic Chemistry Department, Chemistry Institute, UFRGS, Porto Alegre-RS, Brazil. Critical revision, final approval of \\ the version to be published. \\ VIIPhD, Associate Professor, Graduate Studies Program in Pharmaceutical Sciences, Faculty of Pharmacy, UFRGS, Porto Alegre-RS, Brazil. Conception \\ and design of the study, critical revision, final approval of the version to be published.
}

\begin{abstract}
PURPOSE: To evaluate the effects of lipoic acid (thioctic acid) topical application on wound healing on rats skin, and the consequences of lipoic acid nanoencapsulation on this process.

METHODS: The model used was the healing activity on wounds induced by surgical incision on rats skin $(n=44)$. The parameters analyzed (11 days) were wound healing rate and histology (vascular proliferation, polymorphonuclear or mononuclear cells, and collagen synthesis or reepithelialization), after application of free lipoic acid or lipoic acid- loaded nanocapsules. The antioxidant activity of these formulations was evaluated by lipid peroxidation test.
\end{abstract}

RESULTS: It was demonstrated for the first time that the topical application of lipoic acid improves wound healing. On the seventh day after surgery, the animals treated with lipoic acid showed increased healing rate $(60.7 \pm 8.4 \%)$ compared to the negative control group $(43.0 \pm 17.4 \%)$, as so improvement of histological parameters. The nanoencapsulation reverted the pro-oxidant activity presented in vitro by lipoic acid, whereas diminished wound repair.

CONCLUSIONS: The topical application of lipoic acid produced an increase in the skin wound healing, which may be related to its pro-oxidant activity. On the other hand, the nanoencapsulation of the lipoic acid reversed the pro-oxidant activity, although presented minor healing activity.

Key words: Thioctic Acid. Wound Healing. Nanocapsules. 


\section{Introduction}

Lipoic acid (LA), also known as thioctic acid, is a compound present in small amounts in living organisms, which participates in several metabolic processes. LA has properties of metal chelating, reactive oxygen species detention, endogenous antioxidants regeneration and repair of systems ${ }^{1}$. Such actions suggest a possible pro-healing activity. This idea is supported by authors who have demonstrated its inhibitory effect on pro-inflammatory cytokine interleukin-6, so that its oral supplementation exerted beneficial effect on skin wound healing of patients under hyperbaric oxygen therapy ${ }^{2}$. Also, systemical pre-treatment with lipoic acid improved healing of skin wounds induced by abrasion in diabetic rats ${ }^{3}$. However, the wound healing activity of lipoic acid topical application was not established yet. Taking account a possible action when used topically, the dermal use of lipoic acid have been proposed due to its ability of to increase the synthesis of collagen and its deposition in the dermis ${ }^{4}$, from which derives the special interest of its use on skin wound healing. The topical use would also be interesting, since oral administration of lipoic acid may be limited due to its low bioavailability ${ }^{5}$.

Since the lipoic acid is a highly unstable compound, technological alternatives must be developed to permit its delivery in formulations that maintain its functional properties, to allow the topical use of lipoic acid. In this way, our previous reports demonstrated that the incorporation of lipoic acid in lipid-core nanocapsules improves its stability, allowing its formulation in semi-solid formulations, suitable for topical application ${ }^{6,7}$ Furthermore, the polymeric nanoparticles are able to extend and control the lipoic acid release and also enhance its antioxidant effect ${ }^{8}$.

Due to the complexity of the healing process and the involvement of free radicals in this process, there is interest in the study of antioxidants action on skin wound healing. Different in vitro or in vivo studies show conflicting results with regard the role of oxidizing agents in this phenomenon, suggesting that they can accelerate ${ }^{9}$ or even delay $i^{10}{ }^{10}$ Until now, the healing activity of topical application of formulations containing lipoic acid, either free or nanoencapsulated, was not performed.

Thus, this study aimed to assess the possible contribution of topical application of lipoic acid (pure drug) or lipoic acidloaded lipid-core nanocapsules to the healing process, using an in vivo experimental model. Additionally, the relation of the lipoic acid antioxidant activity and the wound healing effect was studied.

\section{Methods}

The procedures follow the Council for International Organization of Medical Sciences (CIOMS) ethical code for animal experimentation and were approved by the Ethics and Research Committee of University of South Santa Catarina, under protocol No 08.365.4.03.V.

Male Wistar rats $(n=44)$ approximately two months old were used, weighing about $130 \mathrm{~g}$, which were kept under controlled temperature $\left(23 \pm 2^{\circ} \mathrm{C}\right)$ and light (12-hour light-dark cycle) with free access to food and water. The animals were randomly divided into four groups receiving different formulations, daily for 11 days. Each group was composed of 11 animals.

\section{Materials}

Poly( $\varepsilon$-caprolactone $)(\mathrm{Mn}=42.500, \mathrm{Mw}=65.000 \mathrm{~g}$ mol1), sorbitan monostearate, thiobarbituric acid, malondialdehyde, iron(II) sulfate and sodium L-ascorbate were supplied by SigmaAldrich $^{\circledR}$ (Strasbourg, France). A caprylic/capric triglyceride mixture was purchased from Brasquim ${ }^{\circledR}$ (Porto Alegre, Brazil), polysorbate 80 from Synth $^{\circledR}$ (Sao Paulo, Brazil), lipoic acid from Pharma Nostra ${ }^{\circledR}$ (Rio de Janeiro, Brazil), trichloroacetic acid from Vetec $^{\circledR}$ (Rio de Janeiro, Brazil), farnesol/linalool from Sarfam ${ }^{\circledR}$ (Sao Paulo, Brazil). The silicon used was sodium polyacrylate (and) dime-thicone (and) cyclopentasiloxane (and) trideceth6(and) PEG/PPG-18/18 dimethicone (Dow Corning RM 2051 ${ }^{\circledR}$ ) from Dow Corning ${ }^{\circledR}$ (Sao Paulo, Brazil). All other chemicals and solvents used were of analytical or pharmaceutical grade. All reagents were used as received.

Preparation of formulations for the topical treatment of

wounds

A suspension of lipoic acid-loaded lipid-core nanocapsules (LALN) was prepared as previous described ${ }^{7}$. Lipoic acid $(2.5 \mathrm{mg} / \mathrm{mL})$ was dissolved in the organic phase composed of triglycerides of capric and caprylic acid $(0.33 \mathrm{~mL})$, sorbitan monostearate $(76.6 \mathrm{mg})$, poly ( $\varepsilon$-caprolactone) $(100 \mathrm{mg})$, acetone PA (26.7 mL), butylhydroxytoluene (10 mg). This organic phase was poured over the aqueous phase containing polysorbate $80(76.6$ $\mathrm{mg})$, diazolidinyl urea $(10 \mathrm{mg})$ and Milli- ${ }^{\circledR}$ water $(53.3 \mathrm{~mL})$, and kept under magnetic stirring for 10 minutes. The formulation was prepared in the dark and evaporated (Büchi ${ }^{\circledR}$ Rotavapor R-114) at a temperature of about $30^{\circ} \mathrm{C}$ until reaching the final volume of 10 $\mathrm{mL}$. 
A semi-solid formulation used as vehicle was prepared with $4 \%$ Silicon and $0.5 \%$ farnesol/linalool (vehicle). The same vehicle was used for the preparation of semi-solid formulations treatments: lipoic acid-loaded lipid-core nanocapsules (LALN) emulsion or lipoic acid (LA) emulsion, both containing lipoic acid at same concentration $(2.5 \mathrm{mg} / \mathrm{ml})$. An emulsion containing allantoin $(0.5 \%)$ was used as positive control. Allantoin dose is the same found in topical products for treating dermatological conditions $^{11}$.

Macroscopic evaluation in rats of the healing activity of lipoic acid

Initially, the healing activity of lipoic acid was evaluated for its ability to heal the wounds produced by surgical incision on the back of rats, measured by the percentage of healing. The wounds were made by removing the tissue layers of the dermis, subcutaneous fat and connective tissue, with subsequent healing by granulation ${ }^{12}$.

The experimental protocol began on the day the animals underwent the surgical procedure (day 0 ).

The animals were anesthetized $(50 \mathrm{mg} / \mathrm{kg}$ ketamine plus $10 \mathrm{mg} / \mathrm{kg}$ xylazine, intramuscular via) and a 2 x $2 \mathrm{~cm}$ surgical wound was performed on the back of the animal using a scalpel. Later, they were placed in individual cages and were monitored until full recovery and received analgesia (100 mg/ml dipyrone sodium, diluted with water provided ad libitum) for four days.

To assess the effects of different treatments, the animals from each group received $0.5 \mathrm{~g} / \mathrm{mm}^{2}$ of each formulation containing lipoic acid or nanoencapsulated lipoic acid, topically applied daily for 11 days. They also underwent treatments that served as controls these being respectively the formulation containing allantoin (positive control) or emulsion vehicle (negative control).

In addition to the daily treatment, all animals were monitored on day zero (surgery day), day 4, day 7, and day 11 after surgery for macroscopic wound evaluation, resulting in the healing rate. For that purpose, they were anesthetized (the same procedure described above), and photographs were taken of the wounds, following the same pattern with regard to the distance, lighting and position of the digital camera Olympus ${ }^{\circledR}$ lens (5.1 megapixel). After the image capture, the wound area was calculated using the Image $\mathbf{J}^{\circledR}$ software, taking the average of three observations for each animal, according to the methodology and care described by Mezadri et al. ${ }^{13}$. The healing rate was calculated by subtracting the average area measured on days 4,7 , and 11 of each animal from to their own average wound area obtained at day zero, which was considered as $100 \%$. Each group was composed of 11 animals.

Histological analysis of the influence of lipoic acid on wound healing

Histological evaluation was another analysis performed on the different groups, from tissues taken from the wounds on days 4, 7, and 11 after surgery. For that purpose, at the end of the macroscopic evaluation in the mentioned days, one animal from each group was euthanized with the use of thiopental sodium $(150 \mathrm{mg} / \mathrm{kg})$. The tissue of the lesion and a surrounding area was removed, keeping the pieces in $10 \%$ formalin for 72 hours, and then paraffin-fixed and subjected to transverse sections of $5 \mu \mathrm{m}$ and stained with hematoxylin-eosin. The analysis was performed by a pathologist who was unaware of the treatments given to the different animals. The findings were rated in intensity and transformed into quantitative variables by assigning scores of 0 (none), 1 (mild), 2 (moderate) or 3 (high) for the following parameters: vascular proliferation, mononuclear cells, polymorphonuclear cells, reepithelialization and collagen synthesis, similar to described by Garros et al. ${ }^{14}$. A Pro Binocular 86 Novex ${ }^{\circledR}$ Microscope with $\mathrm{x} 4$, $\mathrm{x} 10$ and $\mathrm{x} 40$ magnifications was used for scanning.

\section{Antioxidant activity of lipoic acid}

Finally, the antioxidant capacity of in vitro lipoic acid was also evaluated. It was determined from the quantification of the lipid peroxidation inhibition by determining the thiobarbituric acid reactive substances, as described previously with some modification $^{8}$. As a substrate for lipid peroxidation, $250 \mathrm{~mL}$ of an aqueous solution of egg yolk $(10 \%$, w/w) was used. Lipid peroxidation was induced by adding $250 \mu \mathrm{M}$ iron sulfate solution and $500 \mu \mathrm{M}$ sodium ascorbate in $0.1 \mathrm{M}$ Tris- $\mathrm{HCl}(\mathrm{pH} 7.4)$ in the presence of $1.0 \mathrm{mg} / \mathrm{ml}$ lipoic acid-loaded lipid-core nanocapsules or a control solution of $1.0 \mathrm{mg} / \mathrm{ml}$ lipoic acid. Based on these formulations, lipoic acid concentrations, encapsulated or not, of 0.48 or $0.96 \mathrm{mM}$ were tested in the medium, the latter being the highest possible dose to be tested in this experimental protocol from the formulations prepared. Samples without addition of antioxidants were used as control.

All samples were incubated for 60 minutes at $37^{\circ} \mathrm{C}$. Addition of $500 \mathrm{~mL}$ of $12 \%$ trichloroacetic acid solution $\left(\operatorname{Vetec}^{\mathbb{R}}\right.$ ) and $500 \mathrm{~mL}$ aqueous solution of $12 \%$ thiobarbituric acid $\left(\mathrm{Sigma}^{\circledR}\right)$ was made and maintained at $100^{\circ} \mathrm{C}$ for 30 minutes. They were then cooled and centrifuged at $14.300 \mathrm{xg}$ for 12 minutes. The supernatants were quantified at $532 \mathrm{~nm}$ on a spectrophotometer 
(Femto 600 Plus $^{\circledR}$ ). Lipid peroxidation was expressed as the concentration of malondialdehyde formed $(n=5)$ using a standard curve for malondialdehyde $\left(\operatorname{Sigma}^{\circledR}\right)$ in the range of 0.8 to 20 $\mathrm{nmol} / \mathrm{mL}$.

\section{Statistical analysis}

The healing activity is represented as a percentage from the measurements of the wound area (in $\mathrm{mm}$ ) on days 4,7 , and 11 after the incisions, in relation to the day when the surgical procedure was performed (day zero). The antioxidant activity is shown as the amount of malondialdehyde formed (mM) from lipid peroxidation induced by different treatments. These data were analyzed by ANOVA followed by Tukey's test. Statistical differences between mean values \pm SEM were considered significant for $p$ values $\leq$ $0.05 \%\left(\operatorname{GraphPad} 4.0^{\circledR}\right)$.

\section{Results}

Lipoic acid-loaded lipid-core nanocapsules had mean particle size from $313 \pm 2$ to $340 \pm 2 \mathrm{~nm}$, polidispersity of 0.24 \pm 0.003 to $0.29 \pm 0.001$, zeta potencial of $-6.05 \pm 0.06$ to $-7,42$ $\pm 0.38 \mathrm{mV}$ and drug encapsulation efficiency of about $78 \%$. These physicochemical properties are in accordance with the technique for the preparation and the raw materials employed for the preparation of nanocapsules. Also, these characteristics are suitable for incorporation of lipoic acid-loaded lipid-core nanocapsules in semi-solid formulations, intended for cutaneous application $^{6}$.

The skin wound model used in this study has been widely proposed to evaluate wound healing activity of different substances ${ }^{14,15}$. In this study, the skin wounds produced in different groups evolved with exudation and crusting more tenuous in the first seven days, with subsequent crust thickening and epithelial healing and hair growth around the lesion (Figure 1).
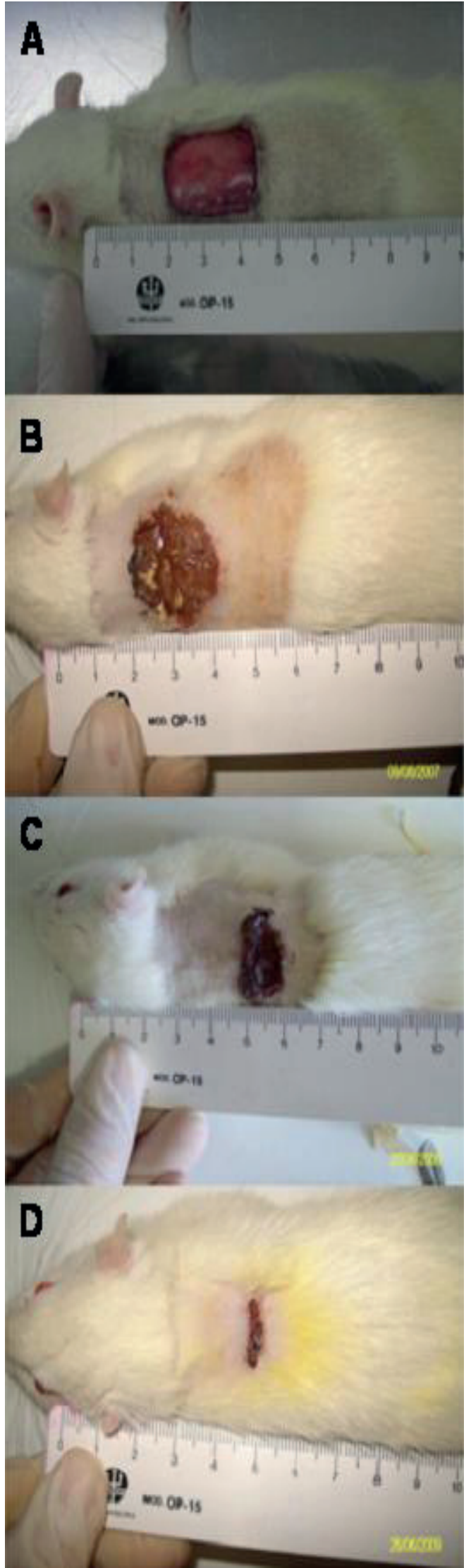

FIGURE 1 - Evolution of skin wounds produced on the back of rats at different days of observation. A: day zero, in which a surgical incision was performed. B, C and $\mathbf{D}$ : days 4, 7, and 11 after surgery, respectively. 
This evolution could be assessed macroscopically, in different days of the experiments that evaluated the healing activity of lipoic acid on skin wounds in rats, through the analysis of digital images using Image $J^{\circledR}$ Program. On day 4 and day 11 after surgery, there was no significant difference $(\mathrm{p}>0.05)$ in percentage healing between groups that received different treatments (Figure 2). However, on day 7 after surgery, there was increasing percentage in the group receiving allantoin (positive control: $56.1 \pm 12.8 \%$ ) compared to the group that received the vehicle (negative control: $43.0 \pm 17.4 \%$ ). Furthermore, skin treatment with lipoic acid showed a healing rate $(60.7 \pm 8.4 \%)$ similar to that induced in the group treated with allantoin and higher than that observed in the group receiving lipoic acid-loaded lipid-core nanocapsules (47.6 $\pm 7.7 \%)$.
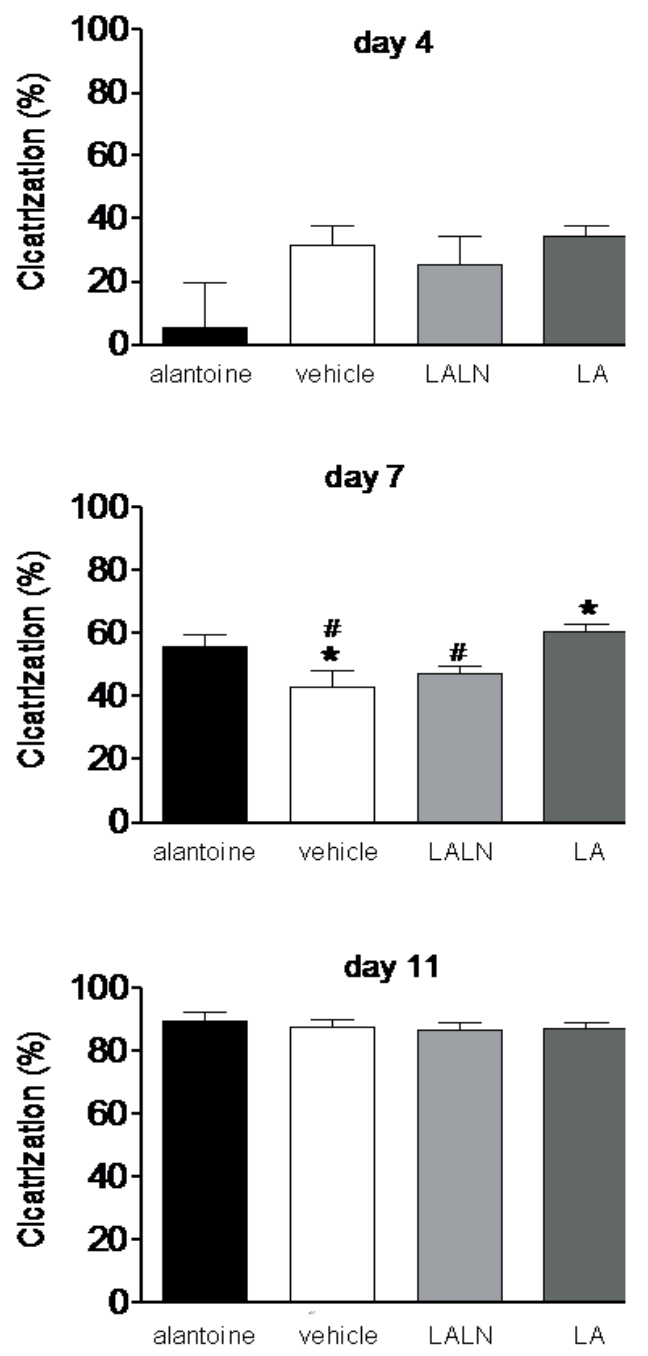

FIGURE 2 - Analysis of the lipoic acid healing activity in skin wounds made by surgical incision on the back of rats on days 4,7 , and 11 after the incisions. Results are presented as means \pm SEM. Asterisks and fences denote statistical difference $(\mathrm{p}<0.05)$ in relation to allantoin or LA groups, respectively (ANOVA followed by Tukey's test).
Regarding the results of histological analysis (Table 1), the data show that in the group receiving lipoic acid-loaded lipidcore nanocapsules the vascular proliferation seems to be increased compared to that observed in animals receiving the other treatments (day 4 after surgery). In the other groups this proliferation occurs in day 7 .

TABLE 1 - Evaluation of different healing parameters, obtained from the histology of tissue removed from wounds in rats treated with different formulations.

\begin{tabular}{|c|c|c|c|c|c|}
\hline \multirow{2}{*}{$\begin{array}{c}\text { Parameter } \\
\text { analyzed }\end{array}$} & \multirow{2}{*}{$\begin{array}{l}\text { Day after } \\
\text { surgical } \\
\text { procedure }\end{array}$} & \multicolumn{4}{|c|}{ Treatment } \\
\hline & & allantoine & vehicle & LALN & LA \\
\hline \multirow{3}{*}{$\begin{array}{c}\text { vascular } \\
\text { proliferation }\end{array}$} & 4 & 2 & 2 & 3 & 2 \\
\hline & 7 & 3 & 3 & 3 & 3 \\
\hline & 11 & 2 & 2 & 3 & 3 \\
\hline \multirow{3}{*}{ polymorphonuclear } & 4 & 3 & 3 & 2 & 1 \\
\hline & 7 & 3 & 2 & 2 & 2 \\
\hline & 11 & 1 & 1 & 2 & 2 \\
\hline \multirow{3}{*}{ Mononuclear } & 4 & 3 & 2 & 2 & 2 \\
\hline & 7 & 3 & 3 & 3 & 2 \\
\hline & 11 & 2 & 2 & 2 & 3 \\
\hline \multirow{2}{*}{ Collagen } & 4 & 1 & 1 & 0 & 1 \\
\hline & 7 & 1 & 1 & 1 & 1 \\
\hline \multirow{4}{*}{ Reepithelialization } & 11 & 2 & 2 & 1 & 2 \\
\hline & 4 & 1 & 0 & 0 & 1 \\
\hline & 7 & 0 & 1 & 1 & 1 \\
\hline & 11 & 2 & 2 & 1 & 2 \\
\hline
\end{tabular}

Different treatment groups: allantoin (positive control), vehicle (negative control), lipoic acid-loaded lipidcore nanocapsules (LALN) or lipoic acid (LA). The different parameters analyzed were classified according to intensity and transformed into quantitative variables by assigning the following scores: $0=$ none, 1 : mild, 2 : moderate or 3 : high.

Additionally, unlike what occurred in the control groups, it was found that animals in groups treated with free or nanoencapsulated lipoic acid, the vascular proliferation remained high on day11, whereas in the other groups this effect appears lower than that observed on day 7. Contrarily, the cellular findings in day 4 or day 7 after surgery showed a more considerable presence of polymorphonuclear cells in allantoin and vehicle groups (negative and positive controls, respectively) than in those treated with free or nanoencapsulated lipoic acid, declining in the last day of observation (day 11). The findings about the presence 
of mononuclear cells in tissues indicated that there is a major presence on day 4 in the allantoin group, while in the others groups this result only occurs on day 7 after surgery. Finally, with regard to reepithelialization and collagen synthesis, which occur in more advanced healing (day 11), the data indicate a tendency of lipoic acid nanoencapsulation in reducing such events.

Finally, it was observed that, on the in vitro assay, the lipoic acid-loaded lipid-core nanocapsules produced antioxidant activity by TBARS method. The presence of nanocapsules contributed for a reduction in the concentration of malondialdehyde formed, the lipid peroxidation main product, (higher dose: $826.9 \pm 49.0 \mathrm{nM}$ ) compared to the control group $(1.760 .3 \pm 120.4 \mathrm{nM})$ (Figure 3). This antioxidant activity was contrary to that observed in samples at the presence of free lipoic acid, which in both the lower and the highest dose tested $(2.211 .5 \pm 275.6 \mathrm{nM}$ and $2,205.1 \pm 60.1$ $\mathrm{nM}$, respectively) increased the malondialdehyde concentration compared to the control group.

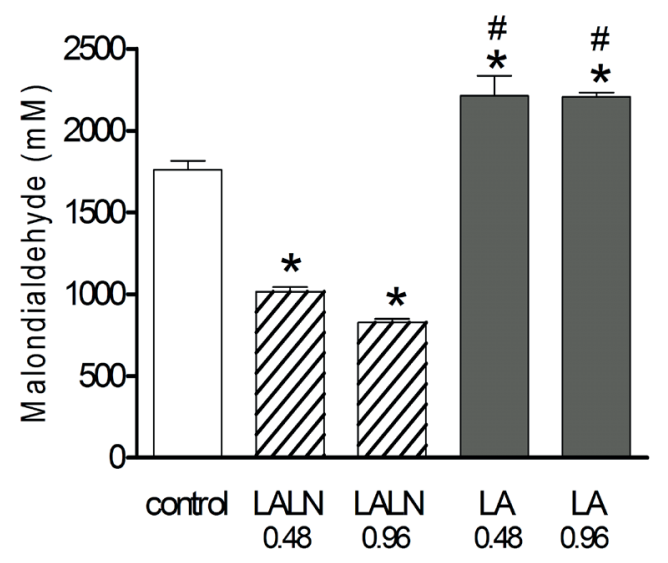

FIGURE 3 - Assessment of malondialdehyde concentration of different lipoic acid formulations at 0.48 or $0.96 \mathrm{mM}$. Samples with the addition of lipoic acid (LA) or lipoic acid-loaded lipid-core nanocapsules (LALN) were compared to those without the addition of antioxidant (control, asterisks) or between corresponding doses for these two formulations (fences). Results are presented as mean \pm SEM. ANOVA followed by Tukey's test $(\mathrm{p}<0.05)$.

\section{Discussion}

The surgical incision method to observe the healing effect of substances has been used by different authors, with some variations in technique for wound induction or to assess the extent of the healing area ${ }^{14,15}$. According to Mezadri et al. ${ }^{13}$, analysis of digital wound images through computerized program that was used in this study with standardization of the image capture process, and using more than one individual for the evaluations, is a reliable and reproducible method. In this work, this technique was able to detect differences between groups on the day 7 after surgery, showing the highest healing effect for animals treated with non-encapsulated lipoic acid. However, the changes produced by this treatment within this period did not shorten the healing time of injuries, since the observations carried out on day 11 revealed no differences between this group and the others.

The healing of skin wounds is a complex and dynamic phenomenon of cellular structure restoration in injured tissues, in which multiple mechanisms and mediators are involved ${ }^{12}$. The role of substances with antioxidant properties in this scenario appears to be still controversial; some authors suggest that the excess of reactive oxygen species may slow the healing process ${ }^{10}$, probably by causing cell membrane lysis. Moreover, as discussed by other authors, a microenvironment at the lesion site constituted by factors such as reactive oxygen species during the early stages of healing, besides acting as antibacterial agents, could contribute to healing, by influencing different phenomena such as hemostasis, inflammation, vascularization, and reepithelialization ${ }^{16}$. According to the latter idea, the pro-oxidative activity of lipoic acid observed in the in vitro assay in this study could be correlated to its ability to produced local cellular stimuli that would result in greater tissue reepithelialization in earlier phases, possibly resulting in higher healing rate observed on the day 7 after surgery on the in vivo assay.

Also, it is known that polymorphonuclear cells are importantly related to the production of reactive oxygen species in tissues, being present in injured tissues since the acute phase ${ }^{12}$. So, agreeing with the idea presented in the previous paragraph, a pro-oxidative activity inherent to the non-encapsulated lipoic acid could explain the histological findings of this study that reported a lower presence of polymorphonuclear cells in the tissue adjacent to the lesion on day 4 after surgery, compared to other groups. This is because the pro-oxidative condition produced by this exogenous component could signal a reduced need for cellular influx at the site. Thus, the loss of pro-oxidant activity of lipoic acid observed in the in vitro assay and induced by the nanoencapsulation process could be responsible for the larger infiltration of polymorphonuclear cells in the tissue studied histologically, in relation to the group treated with non-encapsulated lipoic acid at the same day, turning the healing speed in this group similar to the vehicle group.

It was previously demonstrated that the nanocapsulation increases the physical and chemical stability, as well the antioxidant effect of lipoic acid ${ }^{6,8}$. In this study, although the nanoencapsulation did not provide additional benefits to wound healing, the data support the idea that this is a good technique not only to increase the antioxidant activity, but also to reduce the pro-oxidant activity of the compound. In the in vitro assay, lipoic acid-loaded lipid- 
core nanocapsules showed higher antioxidant activity compared to control group, observed by a less amount of malondialdehyde determined. If the previous idea that the pro-oxidant activity of the compound could result in higher healing, this last finding should be correlated with the process delay. Despite no difference was observed in the healing rate between the animals in the group treated with lipoic acid-loaded lipid-core nanocapsules compared to the control group, this hypothesis can be strengthened by the histological findings of the LALN group that showed less collagen synthesis on day 4 after surgery. The reduction of lipoic acid prohealing potential, by the nanoencapsulation process, could be explained since in healing by second intention the granulation tissue formed by the proliferation of fibroblasts and capillaries is closely related to the collagen synthesis ${ }^{17}$. It is therefore possible that the slower release of lipoic acid from the polymeric nanocapsules ${ }^{8}$ is related to the slower reepithelialization and collagen synthesis (in relation to the allantoin group, day 4 after surgery) in this group.

The dual behavior of substances that can be both prooxidant and antioxidant is not new, since this effect has already been described for several drugs (vitamin C, Vitamin E or coenzyme Q10, for example). Lipoic acid has also shown both pro-oxidant and antioxidant activities ${ }^{18}$. While its antioxidant properties include the ability to chelate metals, retain reactive oxygen species and regenerate endogenous antioxidants ${ }^{1}$, their pro-oxidant actions depend on the biological system, the type of oxidant stress and the physiological circumstances ${ }^{18,19}$.

In this study, although the nanoencapsulation did not provide additional benefits to wound healing, the data support the idea that this is a good technique to reduce the pro-oxidant activity of the compound. The results suggest a dual action of lipoic acid in the early stages of the healing process, depending on the antioxidant activity and the amount released into the skin tissue.

\section{Conclusions}

Topical application of non-encapsulated lipoic acid produced an increase in the skin wound healing, which may be related to alterations of histological parameters and its pro-oxidant activity. On the other hand, the nanoencapsulation of the lipoic acid reversed the pro-oxidant activity, producing antioxidant activity, although demonstrating a minor healing activity.

\section{References}

1. Biewenga GP, Haenen GRMM, Bast A. The pharmacology of the antioxidant lipoic acid. Gen Pharmacol. 1997;29:315-31.

2. Alleva R, Nasole E, Donato FD, Borghi B, Neuzil J, Tomasetti
M. $\alpha$-Lipoic acid supplementation inhibits oxidative damage, accelerating chronic wound healing in patients undergoing hyperbaric oxygen therapy. Biochem Biophys Res Commun. 2005;333:404-10

3. Lateef H, Aslam MN, Stevens MJ, Varani J. Pretreatment of diabetic rats with lipoic acid improves healing of subsequently-induced abrasion wounds. Arch Dermatol Res. 2005;297:75-83.

4. Han B, Nimni ME. Transdermal delivery of amino acids and antioxidants enhance collagen synthesis: in vivo and in vitro studies. Connect Tissue Res. 2005;46:251-7.

5. Breithaupt-Grögler K, Niebch G, Schneider E, Erb K, Hermann R, Blume HH, Schug BS, Belz GG. Dose-proportionality of oral thioctic acid - coincidence of assessments via pooled plasma and individual data. Eur J Pharm Sci. 1999;8:57-65.

6. Külkamp-Guerreiro IC, Terroso TF, Assumpção ER, Berlitz SJ, Contri RV, Pohlmann AR, Guterres SS. Development and stability of innovative semisolid formulations containing nanoencapsulated lipoic acid for topical use. J Nanosci Nanotechnol. 2012;12:772332.

7. Külkamp IC, Paese K, Pohlmann AR, Guterres SS. Estabilização do ácido lipoico via encapsulação em nanocápsulas poliméricas planejadas para aplicação cutânea. Quim Nova. 2009;32:2078-84.

8. Külkamp IC, Rabelo BD, Berlitz SJ, Isoppo Mateus, Bianchin MD; Schaffazick SR, Pohlmann AR, Guterres SS. nanoencapsulation improves the in vitro antioxidant activity of lipoic acid. J Biomed Nanotechnol. 2011;7:598-607.

9. Haas AF, Wong JW, Iwahashi CK, Halliwell B, Cross CE, Davis PA. Redox regulation of wound healing? NF-kappaB activation in cultured human keratinocytes upon wounding and the effect of low energy HeNe irradiation. Free Radic Biol Med. 1998;25:998-1005.

10. Shetty S, Udupa S, Udupa L. Evaluation of Antioxidant and Wound Healing Effects of Alcoholic and Aqueous Extract of Ocimum sanctum Linn in Rats. Evid Based Complement Alternat Med. 2008;5:95-101.

11. Arad A, Mimouni D, Ben-Amitai D, Zeharia A, Mimouni M. Efficacy of topical application of eosin compared with zinc oxide paste and corticosteroid cream for diaper dermatitis. Dermatology. 1999; 199:319-22.

12. Clark RA. Biology of dermal wound repair. Dermatol Clin. 1993;11:647-66.

13. Mezadri TJ, Leite MF, Staack Júnior MC, Colchon PH, Balan AB, Zanatta ML, Costa IC, Perin C, Tames DR, Sousa JPB, Bastos JK, Andrade SF. Evaluation of the contraction of cutaneous wounds in wistar rats treated with brazilian green propolis gel. Lat Am J Pharm. 2009;28:762-7.

14. Garros IC, Campos ACL, Tâmbara EM, Tenório SB, Torres, OJM, Agulham MA, Araújo ACF, Santis-Isolan PMB, Oliveira RM, Arruda ECM. Extrato de passiflora edulis na cicatrização de feridas cutâneas abertas em ratos: estudo morfológico e histológico. Acta Cir Bras. 2006;21:55-65.

15. Atzingen DANCV, Gragnani A, Veiga DF, Abla LEF, Mendonça ARA, Paula CA, Juliano Y, Correa JC, Faria MR, Ferreira LM. Gel from unripe Musa sapientum peel to repair surgical wounds in rats. Acta Cir Bras. 2011;26:379-82.

16. Sen CK, Roy S. Redox signals in wound healing. Biochim Biophys Acta. 2008;1780:1348-61.

17. Mcnees P. Skin and wound assessment and care in oncology. Semin Oncol Nurs. 2006;22:130-43.

18. Çakatai U. Pro-oxidants action of alfa lipoic acid and dihydrolipoic acid. Med Hypotheses. 2006;66:110-7.

19. Moini H, Packer L, Saris NEL. Antioxidant and prooxidant activities of $\alpha$-lipoic acid. Toxicol Appl Pharmacol. 2002;182:84-90. 


\section{Acknowledgements}

To Renê Darela Blazius, Luiz Alberto Kanis, Gabriela Garrastazu Pereira and Rosanne Platcheck for contributions.

\section{Correspondence:}

Irene Clemes Külkamp-Guerreiro

Universidade Federal do Rio Grande do Sul

Faculdade de Farmácia

Programa de Pós Graduação em Ciências Farmacêuticas

Avenida Ipiranga, 2752/Sala 307

90610-000 Porto Alegre - RS Brasil

Tel.: (55 51)3308-5416

irene@ufrgs.br

Received: June 12, 2013

Review: Aug 14, 2013

Accepted: Sept 12, 2013

Conflict of interest: none

Financial sources: National Council of Technological and Scientific Development (CNPq), Coordination of Improvement for Higher Academic Staff (CAPES), Studies and Projects Finance Organization (FINEP), University of South Santa Catarina and Federal University of Rio Grande do Sul

${ }^{1}$ Research performed at Laboratories of University of South Santa Catarina and Federal University of Rio Grande do Sul (UFRGS), Brazil. Part of $\mathrm{PhD}$ degree thesis, Postgraduate Program in Pharmaceutical Sciences. Tutor: Profa. Dra. Sílvia Stanisçuaski Guterres. 